\title{
LUNAR DREAMS
}

Fifty years after Apollo, Nature profiles five researchers whose work will shape the next half century of Moon science.

\section{BY ALEXANDRA WITZE}

M egha Bhatt grew up gazing at the Moon riding through the blackest of skies. Electricity was often off at night in her small village in India, so there was plenty of time to marvel at the celestial views. Her parents told her stories of how American men had gone to the Moon and taken a giant step there. At school, she saw a video of Neil Armstrong on the lunar surface, and she was hooked. She became a planetary scientist.

Next week, Bhatt intends to watch her own country reach for the Moon. In the early hours of 15 July, at the Satish Dhawan launch centre north of Chennai, the Chandrayaan-2 lunar probe is scheduled to thunder into space. If it takes off successfully, the spacecraft will head for the Moon's south pole and drop India's first lunar lander to the surface. This carries a six-wheeled roving robot, which would make India the fourth nation, after the Soviet Union, the United States and China, to place a wheeled vehicle on another world.

Chandrayaan-2 highlights just how much has changed in lunar exploration in the 
50 years since Armstrong took those historic steps. A field that was once the realm of a handful of white US men - flying to the Moon in the series of missions known as Apollo - is now much younger, more diverse and dominated by robots.

Beyond the Indian mission, China made a historic landing on the lunar far side in January and might launch its first sample-return mission later this year. In April, an Israeli company put the first privately built spacecraft on the Moon (although it crash-landed). South Korea is developing its first lunar probe, for launch as early as next year. Russia is working on a series of landers that would be its first return to the Moon in decades. And the United States has announced plans to send a set of robotic probes in the run-up to putting astronauts back on the lunar surface by the end of 2024 (see page 153). "It's a golden period for Moon exploration," says Bhatt.

With all these opportunities opening up, a new generation of scientists is rushing to embrace lunar science. None of these researchers was alive when NASA's astronauts walked on the Moon between 1969 and 1972, but the significance of Apollo resonates across the decades. Nature spoke to five young lunar researchers, whose experiences show just how much interest there is in Earth's nearest neighbour - and how much remains to be discovered there.

\section{MEGHA BHATT: MINERAL MAVEN}

Bhatt has been feeling the tug of the Moon throughout her life. As a child, she dreamed of working for India's space agency, which motivated her to study physics and electronics. She read books written by Apollo astronauts including Buzz Aldrin, the second person to set foot on the Moon. Later, while doing her $\mathrm{PhD}$ at the Max Planck Institute for Solar System Research in Göttingen, Germany, she became friendly with a quiet Russian scientist visiting the institute. Only when she saw him on a television programme did she realize that Sasha Basilevsky was one of the key lunar geologists in the Soviet space programme, the person who helped determined where the first two Moon rovers landed in 1970 and 1973.

Bhatt built her career at perhaps the perfect time to be a lunar scientist in India. The country launched its first Moon mission, the Chandrayaan-1 orbiter, in 2008. She used data from several of its instruments for her $\mathrm{PhD}$, which explored lunar mineralogy. By studying how light reflects off the Moon at various wavelengths, she mapped how different minerals are distributed across the surface. She helped to develop a method for estimating iron abundances $^{1}$, information that can reveal how the molten infant Moon began to form mineral crystals as it cooled some 4.5 billion years ago.

Now at India's national Physical Research

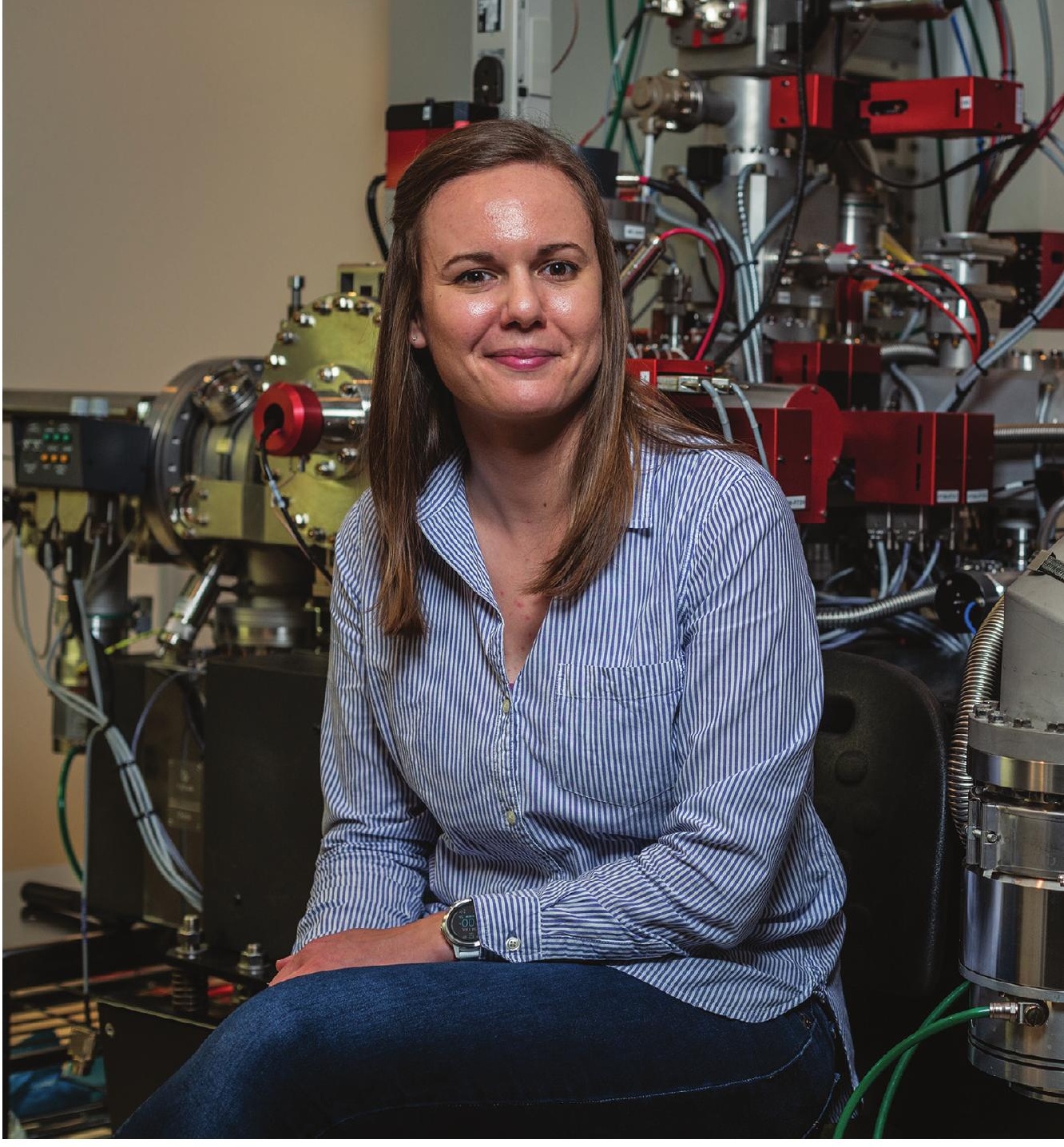

\section{"IT'S THE MOST BEAUTIFUL ROCK I'VE EVER SEEN."}

Laboratory in Ahmedabad, Bhatt continues to specialize in remote sensing of the Moon, building maps of its mineralogy. She works mostly with data from Chandrayaan-1, but pieces those together with measurements from other lunar missions such as Japan's SELENE probe, which orbited between 2007 and 2009. "You have to integrate to see the bigger picture," she says. "It's like a detective job."

One of the Moon mysteries she is trying to unravel is that of lunar swirls. These enigmatic light-coloured markings appear across the Moon, like splotches of cream in coffee. Scientists have several competing ideas about how lunar swirls form, but one popular notion is that magnetic rocks in places act like a protective umbrella to shield the surface from the stream of cosmic particles known as the solar wind. The shielding keeps the surface from darkening as much as it would otherwise.

Bhatt has been studying the mineralogy of these swirls, which can stretch for tens of kilometres. In one swirl, a looping feature known as Reiner Gamma, Bhatt has found variations in the way that the surface minerals reflect light, which suggests that several mechanisms formed different regions of the swirl. The magnetic shielding can explain some parts of some lunar swirls, she says, but perhaps not all of them.

If the Chandrayaan-2 mission is successful, Bhatt will turn her attention to the minerals at the rover's landing site. The lander will be the first probe to settle on the iron-poor, aluminium-rich rocks of the lunar highlands - a region whose chemistry has never been explored directly before.

And that could turn up all sorts of surprises. "The whole lunar community is looking forward to this mission," Bhatt says.

\section{JESSICA BARNES: ROCK DETECTIVE}

Some time in the next year or so, Jessica Barnes will walk into a big freezer, maintained at a frigid $-20^{\circ} \mathrm{C}$, and lay her gloved hands on a piece of Moon rock that has been kept frozen ever since astronauts brought it back to Earth in 1972. It will be the first time these Apollo samples have been opened, and no one is entirely sure what they might contain.

Barnes plans to analyse the frozen rock for how much water and other volatile materials it contains. Astronaut Harrison Schmitt chipped it off a boulder in the Taurus-Littrow valley on the Moon, at the same time taking another chunk from the same boulder. That sample 


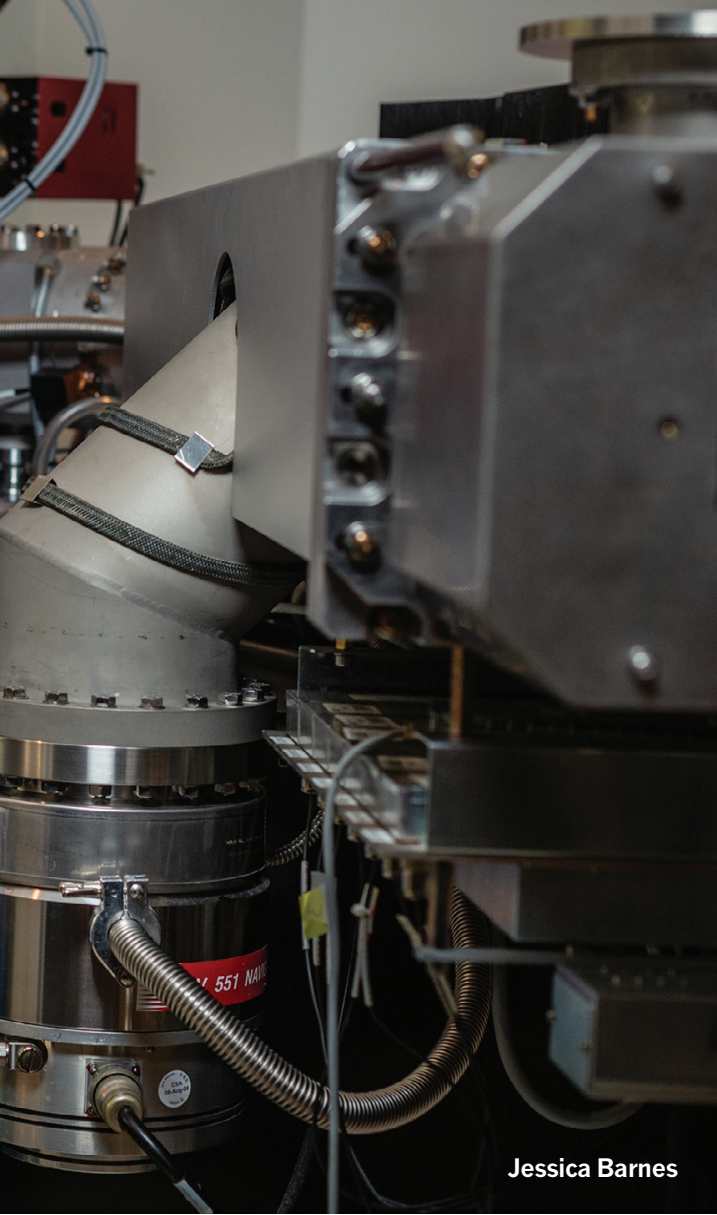

was kept at room temperature after returning to Earth. Barnes now has an unparalleled chance to study how the two differ.

If they contain the same amount of water and other volatiles, then NASA might not have to bother with freezing the rocks when they return from the Moon. Any differences $\sum$ could point to new ways of curating lunar samples to keep their scientific value intact for many years. Only in 2008 did researchers unambiguously detect water in Apollo samples for the first time, meaning that the Moon isn't as bone-dry as so many had thought for generations. Barnes and her colleagues will also probe the basic geology and chemistry of the frozen Apollo sample.

Barnes started out as a geology student in Scotland, but switched to the Moon when she stumbled on $\mathrm{PhD}$ position that involved analysing chemical elements in lunar rocks at an extremely small scale using a technique called nanoscale secondary ion mass spectrometry ${ }^{2}$. "I took a look at the position and couldn't believe my luck," she says. "I'd be studying Moon rocks using a brand-new technique. I was fortunate enough to get it, and I've never looked back."

She now works at NASA's Johnson Space Center campus in Houston, Texas, not far from the famed lunar lab where the Apollo rocks are carefully preserved for scientific research. She studies a variety of Moon rocks, including her favourite - an ancient rock known as a troctolite, its milky-white body studded with honeybrown minerals. "It's the most beautiful rock I've ever seen," she says. In August, she will move to the University of Arizona in Tucson, where she will apply lessons from the Moon rock studies to help plan how to preserve asteroid samples collected by OSIRIS-REx, the first US mission to return from an asteroid, which is expected back in 2023.

For now, her biggest excitement is being part of the Apollo sampling programme, which includes eight other teams looking at different aspects of pristine Apollo rocks. And every once in a while Barnes goes to a meeting and sees Schmitt - the astronaut who picked up her very own rock sample on the Moon.

\section{KATHERINE JOY: METEORITE HUNTER}

The lunar rocks that Katherine Joy studies at the University of Manchester, UK, didn't arrive in a space capsule, hand-delivered by astronauts. She specializes in lunar meteorites, rare fragments of the Moon that were knocked free by a cosmic impact and then flew through space to land on Earth.

Joy even hunts for meteorites herself, sometimes whizzing across vast Antarctic icefields on a snowmobile. As she drives across the frozen surface, she scans it for small dark rocks that visually pop against the reflective ice. These are meteorites that fell onto Antarctica's ice and are just waiting for scientists to pick them up.

Earlier this year, Joy participated in the first UK-led Antarctic meteorite search, organized and supported by the British Antarctic Survey in Cambridge. Over the course of 4 weeks, the team found 36 space rocks on the ice.

This month, she will get her first real shot at analysing those samples, which have just arrived in the United Kingdom on the slow boat that has carried them from Antarctica.

She hopes to identify at least one rock that began its journey on the Moon. "We've managed to find pieces of [the asteroid] Vesta on one of the trips I've been on," she says. "But I'm desperate to find a lunar meteorite."

Joy, a geochemist, has studied some of the most famous rocks brought back by the Apollo astronauts. In 2012 she reported

Chae Kyng Sim finding fragments of ancient asteroids in rocks gathered during the Apollo 16 mission $^{3}$ - a result that suggests that chemically primitive asteroids regularly bombarded Earth and the Moon more than 3.4 billion years ago.

Lunar meteorites could help Joy expand her work because they hail from all over the Moon. The Apollo samples, by contrast, all come from a relatively limited part of the Moon, which is a geochemically unique area on the lunar near side.

Scientists have identified more than 145 lunar meteorites, and look to them to understand the broader geology of the Moon. In May, for instance, Joy and her colleagues reported that a 4.3-billion-year-old lunar meteorite found in Antarctica in 2013 contains evidence that volcanoes were already erupting on the Moon at that time, hundreds of millions of years before the main period of lunar volcanism kicked off. The work adds to growing evidence that volcanoes erupted earlier in lunar history than researchers had thought.

Joy is part of a collaboration building a European instrument for Russia's planned Luna-27 lander, which aims to visit the Moon's south polar region some time after 2023. She has also advised the UK government on the importance of planetary exploration. She'd like nothing more than to travel to the Moon herself, perhaps to rappel down the side of an impact crater in search of layers of geological history.

For now, though, she will have to make do with the meteorites she picks up in Antarctica. The team has funding for one more field season and is hoping to establish it as a permanent programme, a UK complement to the long-running US-led Antarctic meteorite hunt that happens every year.

Every time Joy and her colleagues spot a dark speck on the ice, she hopes it is a lunar meteorite, a potential treasure trove of information about the Moon conveniently dropped here on Earth. "That's why we keep going back to get more," she says.

\section{CHAE KYUNG SIM:}

\section{SOIL SLEUTH}

Chae Kyung Sim definitely does not want to travel to the

Moon. Squashed into her aeroplane seat on a recent trip from South Korea to Texas, she tried to pass the time by watching the film First Man, which dramatizes Neil Armstrong's journey to the Moon. Seeing him in the Apollo capsule made a 
deep impression on Sim during her uncomfortable flight. "It was so hard to watch him squeezed in the spacecraft," she says.

Sim much prefers to take her two children out to look at the Moon in the sky. They talk about its brightness and its changing shape, and about how their mother is working to unravel many of its mysteries from right here on Earth.

Inspired by a childhood friend who loved astronomy, Sim originally trained as a planetary astronomer and studied the atmospheres of Jupiter and Saturn. But around the time she got her PhD, in 2014, the South Korean government announced plans to send the nation's first spacecraft to the Moon. There were very few Korean lunar scientists at the time, so Sim and others scrambled to dream up unique science for the mission.

She is now part of a team that is developing a camera that will use polarized light to study the Moon. Polarimetric studies can reveal details of the lunar surface such as how big the dust particles are, which is a sign of how weathered the surface is. The camera will be the highest-resolution polarimetry instrument ever sent to the Moon and will allow scientists to plan for future missions to the surface, says Sim, who is a planetary scientist at Kyung Hee University in Seoul.

Her speciality is space weathering, the process by which a planet's surface gets darker

\section{"IT WAS SO HARD TO WATCH HIM SQUEEZED IN THE SPACECRAFT."}

and redder over time as it is bombarded by meteorite impacts and by the solar wind. Sim has worked to unravelling how much of space weathering on the Moon is caused by those two processes. Untangling the various factors that degrade the surface can help researchers understand the geological history of an area, she says.

In a paper in the press at Icarus ${ }^{4}$, she and her colleagues found that the amount of iron in lunar soils can cause them to respond differently to space weathering. Understanding those differences could help mission planners to select the types of soil on which they might land a spacecraft.

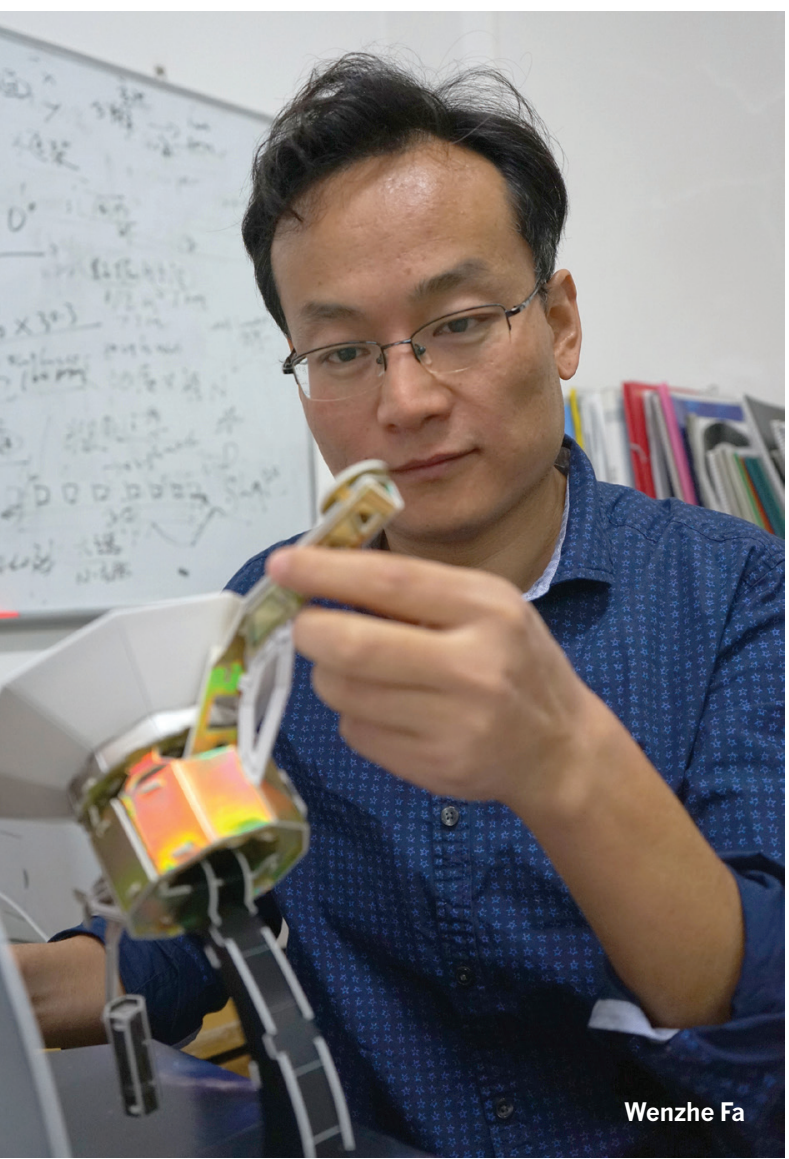

for the slot. Finally, he would be able to contribute to home-grown discoveries.

Now a lunar scientist at Peking University in Beijing, Fa has spent years immersed in Chinese Moon data. He is on the science team for Change-4, which made the historic far-side landing. And his publications list is loaded with discoveries from the first three Chang'e missions.

He has calculated the amount of helium-3 - a potential fuel source for astronauts - in the lunar soil, and measured the depths of various soil layers beneath the Chang'e-3 rover. The craft touched down in the Mare Imbrium region in 2013 and carried a ground-penetrating radar instrument. It made the most detailed measurements yet of the lunar subsurface, which turned out to be more geologically complicated than scientists had expected. "The more we explore the Moon, the more questions we have," Fa says.

Fa has also challenged conventional wisdom, such as whether shadow-draped craters near the lunar poles contain large amounts

The South Korean government has talked about future lunar missions, including an eventual lander. For now, its first step towards the Moon - the Korea Pathfinder Lunar Orbiter - is scheduled for launch no earlier than the end of 2020. Once the data start flowing back, Sim expects to use them to compare space weathering on the Moon with that on other airless bodies, such as Mercury. She is also looking forward to showing the world whatever the Korean probe finds.

"As a foreigner, I felt uncomfortable to use other countries' data, because the money was spent by taxpayers of that country and not our country," she says. "I want to share Korean data to scientists from other countries."

\section{WENZHE FA: RADAR READER}

Wenzhe Fa also saw his career shaped by his country's lunar ambitions. He grew up in the countryside in northwestern China, and studied physics and chemistry, which led him to a university - and a big city. But in his textbooks, most of the scientists described were from Western countries. "There were no Chinese names," he says.

By the time he started his doctorate at Fudan University in Shanghai, Fa was studying satellite measurements of the Earth and specializing in the physics of how energy scatters off planetary surfaces. And China was gearing up to launch its first Moon orbiter, Change-1, in 2007. The lab he worked in was going to work on data from the probe and Fa volunteered of ice. Observations from spacecraft, including the US Lunar Reconnaissance Orbiter, have found signatures of water ice in these craters, and space agencies such as NASA say that astronauts could mine this ice to support future lunar colonies. But Fa developed a new model for explaining the observations ${ }^{5}$. He suggests that the US lunar orbiter was seeing radar bouncing mostly off rocks, not ice. "There could be water ice, but the volume is not as much as previously thought," he says. "My result really is a challenge for future exploration."

Looking ahead, $\mathrm{Fa}$ is already planning for the Change- 5 mission, which China aims to launch as early as this year to retrieve lunar samples and deliver them to Earth. He has seen, but never touched, Moon rocks collected by the Apollo astronauts. Now, with a Chinese spacecraft scheduled to bring back as much as 2 kilograms of lunar material, he may finally have his chance to connect with the Moon, he says. "Sometimes I think I am very lucky." -

Alexandra Witze writes for Nature from Boulder, Colorado.

1. Bhatt, M., Mall, U., Wöhler, C., Grumpe, A. \& Bugiolacchi, R. Icarus 248, 72-88 (2015).

2. Barnes, J. J. et al. Chem. Geol. 337-338, 48-55 (2013).

3. Joy, K. H. et al. Science 336, 1426-1429 (2012).

4. McFadden, J., Garrick-Bethell, I., Sim, C. K., Kim, S. S. \& Hemingway, D. Icarus 333, 323-342 (2019).

5. Fa, W. \& Cai, Y. J. Geophys. Res. Planets $\mathbf{1 1 8 ,}$ 1582-1608 (2013) 